\title{
Cytochemical bioassay of parathyroid hormone in maternal and cord blood
}

\author{
J ALLGROVE, S ADAMI, R M MANNING, AND J L H O'RIORDAN
}

Department of Medicine, Middlesex Hospital, and Division of Cellular Biology, Mathilda and Terence Kennedy Institute of Rheumatology, London

SUMMARY Parathyroid hormone and calcium were measured in plasma taken from pregnant women at term and from the umbilical veins of their infants at birth. Three assays were used to measure parathyroid hormone, a cytochemical bioassay of bioactivity and two immunoradiometric assays, one specific for the amino terminus, the other specific for the carboxy terminus of the parathyroid hormone molecule.

Plasma calcium was significantly higher in the infants than in the mothers. Maternal parathyroid hormone bioactivity and the amino terminus were both slightly raised, but the carboxy terminus value was normal; these findings supported the view that late pregnancy is a time of mild physiological hyperparathyroidism. In the infants, the amino terminus was undetectable and the carboxy terminus was either undetectable or towards the lower end of the normal range: bioactivity of parathyroid hormone was considerably raised and was related to the gradient of calcium across the placenta. This suggests that the parathyroid glands are not suppressed during fetal life and that they may play an important part in the maintenance of high fetal plasma calcium concentrations.

It has long been recognised that the total concentration of calcium in maternal plasma falls during pregnancy, particularly during the last trimester. ${ }^{1}$ This fall is largely accounted for by a reduction in the plasma albumin concentration, ${ }^{2}$ but there is some disagreement over whether or not the concentration of ionised calcium changes significantly. ${ }^{3-5}$ In the fetus, however, the total concentration of calcium rises during fetal life, ${ }^{2}$ and it has been known since 1923 that by term it is significantly greater than that of maternal plasma ${ }^{6}$ This observation has been confirmed repeatedly, ${ }^{78}$ and it is known to be true also of ultrafilterable ${ }^{9}$ and ionised calcium. ${ }^{1011}$ At birth the difference between the total calcium concentration is 0.25 to $0.5 \mathrm{mmol} / \mathrm{l}$ even when differences in serum albumin are allowed for. The mechanisms by which this gradient is maintained have not been adequately explained.

Parathyroid hormone has been measured in maternal and cord plasma by immunoassay in several studies. A rise in immunoreactive parathyroid hormone has frequently been described in the maternal circulation during gestation, ${ }^{12} 13$ although there has been some disagreement on this point. ${ }^{11}$ 14-17 Pregnancy has been described as a condition of physiological hyperparathyroidism ${ }^{12}$ but it has not been established whether this is a primary event associated with the increased calcium retention and bone turnover known to occur from the middle of pregnancy onwards, ${ }^{18}$ possibly in anticipation of fetal calcium requirements. It may be a secondary event in response to the demand for calcium by the fetus during the last trimester.

Similar studies in the fetus have produced very conflicting results. In some, the concentrations of parathyroid hormone in cord blood were low or undetectable and maternal concentrations were either not measured, ${ }^{19-22}$ were normal, ${ }^{15} 1623$ or were raised. ${ }^{5}{ }^{13}$ In other studies, the concentrations in both fetal and maternal plasmas were within the normal adult range, ${ }^{11} 141724$ while in others both maternal and cord samples contained high concentrations. ${ }^{25} 26$ In no reports have the concentrations of parathyroid hormone in fetal plasma been higher than those of maternal plasma. It has been suggested that, as a result of the high fetal plasma calcium, the fetal parathyroid glands are suppressed during fetal life ${ }^{24}$ despite the fact that they are capable, from 12 weeks' gestation, of producing a substance, presumably parathyroid 
hormone, which is immunochemically indistinguishable from parathyroid hormone ${ }^{27}$ and which causes bone resorption in vitro. ${ }^{28}$ Recent evidence in primate $^{29}$ suggests that the response of fetal glands to induced hypocalcaemia is similar to that of the mother.

We have studied the problem using three different assays for parathyroid hormone, namely a highly sensitive cytochemical bioassay, which measured bioactivity, and two immunoradiometric assays which employed homologous antihuman parathyroid hormone antibodies, one specific for the amino terminus, the other specific for the carboxy terminus of the parathyroid hormone molecule.

\section{Patients and methods}

Blood samples were obtained from the umbilical veins of 10 normal term infants immediately after their cords had been clamped and before delivery of the placenta. Simultaneous venous blood samples were obtained from the mothers. All specimens for parathyroid hormone assay were taken into cold heparinised tubes and kept on ice until centrifuged at $4^{\circ} \mathrm{C}$. This was done as soon as possible after each specimen had been obtained. Plasma for cytochemical bioassay was snap frozen to $-70^{\circ} \mathrm{C}$ in aliquots of about $150 \mu \mathrm{l}$, and those for immunoassay in aliquots of $1 \mathrm{ml}$. Aliquots of the same samples were also taken for measurement of calcium, albumin, and phosphate.

The cytochemical bioassay was performed as previously described ${ }^{30}$ on samples from eight of the mother and baby pairs. Parathyroid hormone bioactivity was measured by its ability to stimulate glucose 6-phosphate dehydrogenase (G6PD) in distal convoluted tubules of guinea pig kidneys. Samples were assayed against a standard preparation of bovine hormone (77/533 NIBSC) and all results were expressed as $\mathrm{pg} / \mathrm{ml}$ of this standard. The limit of sensitivity of this assay is $0 \cdot 1 \mathrm{pg} / \mathrm{ml}$ when the initial dilution is $1: 100$ and the normal range for young adults is 1.1 to $5.9 \mathrm{pg} / \mathrm{ml}$. Immunoradiometric assays for N-PTH and C-PTH were performed as previously described ${ }^{31} 32$ using homologous antibodies selected for high affinity to the respective terminals of the parathyroid hormone molecule. The limit of detection of the amino terminus assay is $40 \mathrm{pg} / \mathrm{ml}$ of 1-34 human parathyroid hormone standard and the upper limit of normal for adults is $120 \mathrm{pg} / \mathrm{ml}$. Two thirds of normal subjects have undetectable amino terminus concentrations in plasma. The limit of detection of the carboxy terminus assay is $100 \mathrm{pg} / \mathrm{ml}$ of 53-84 human parathyroid hormone standard and the upper limit of normal is $800 \mathrm{pg} / \mathrm{ml}$; the carboxy terminus can be detected in all normal subjects. Calcium, phosphate, and albumin were measured by automated techniques on a Vickers M300 autoanalyser and all calcium values were corrected for plasma albumin.

To assess the nature of parathyroid hormone bioactivity in fetal plasma, a time course of the activity of G6PD in guinea pig kidney renal tubules in response to exposure to fetal plasma was compared with that of the response to maternal plasma. In another experiment antibody was added to the fetal plasma before assay to see if parathyroid hormone bioactivity was eliminated. The antibody used for this was the same as that used for the amino terminus immunoradiometric assay, and was added to the plasma in a dilution of 1:100. A similar concentration of extraction medium was added to the plasma being assayed.

\section{Results}

The concentrations of calcium, corrected for albumin; the amino terminus; the carboxy terminus; and parathyroid hormone bioactivity found in maternal and cord plasma are shown in Figs. 1 and 2. The calcium concentrations were mean (SEM), 2.46 $(0.02) \mathrm{mmol} / \mathrm{l}$ in maternal plasma and $2.70(0.04)$ $\mathrm{mmol} / \mathrm{l}$ in cord plasma. This difference was highly significant $(\mathrm{P}<0 \cdot 001)$. The amino terminus was raised in four of the maternal samples (mean (SEM), $173(27) \mathrm{pg} / \mathrm{ml}$ ) but was undetectable in all the cord plasma samples. Even if it is assumed that undetectable values were at the limit of detection of the assay, the difference between these two groups was significant $(\mathrm{P}<0 \cdot 001)$. The carboxy terminus of parathyroid hormone was within the normal range in all the maternal samples, and within the normal range in five, but undetectable in two, of the fetal samples. Bioactivity of parathyroid hormone was significantly raised (mean (SEM), 7.1 (1.4) pg/ml; $\mathbf{P}<0.02$ ) in maternal plasma, although four of the values were within the normal range. In cord plasma, however, in contrast to the findings with immunoassay, concentrations were considerably raised (mean (SEM) $41(6.5) \mathrm{pg} / \mathrm{ml}$ ), and the difference between maternal and cord samples was highly significant $(\mathrm{P}<0 \cdot 001)$.

The time courses of response of G6PD to maternal and cord plasma are shown in Fig. 3. The response was parallel in the two samples, with an initial peak response at six minutes. Addition of antibody against parathyroid hormone to cord plasma before assay (Fig. 4) eliminated the bioactivity.

There was no relation between plasma calcium and bioactivity of parathyroid hormone in either group of subjects. There was also a significant 
112 Allgrove, Adami, Manning, and O'Riordan

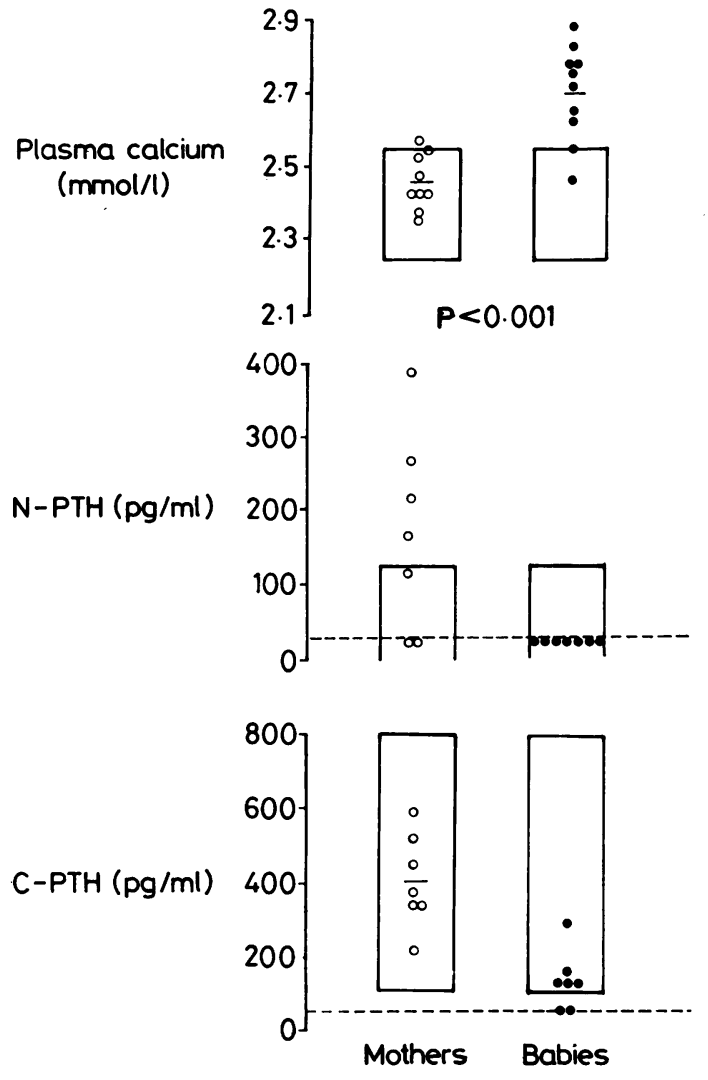

Fig. 1 Plasma calcium, amino terminal parathyroid hormone (N-PTH), and carboxy terminal parathyroid hormone (C-PTH) in maternal (open circles) and cord (closed circles) venous plasma.

The normal ranges for adults are shown by the rectangles and the limits of detection of the immunoassays by horizontal interrupted lines. For purposes of data analysis, undetectable values were assumed to be at the limit of detection of the assays.

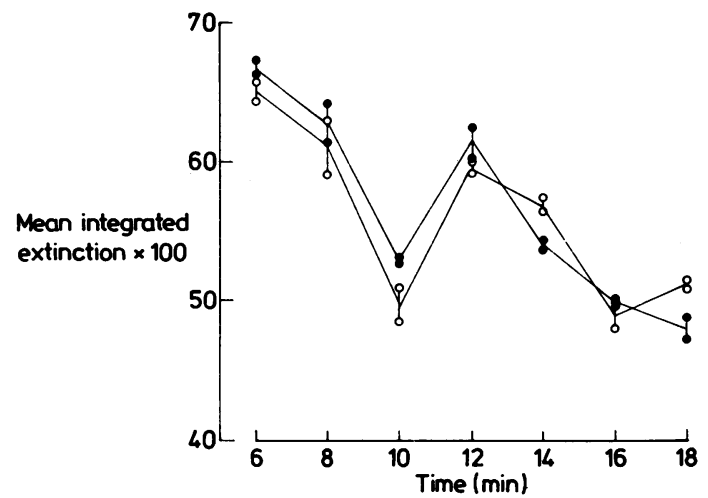

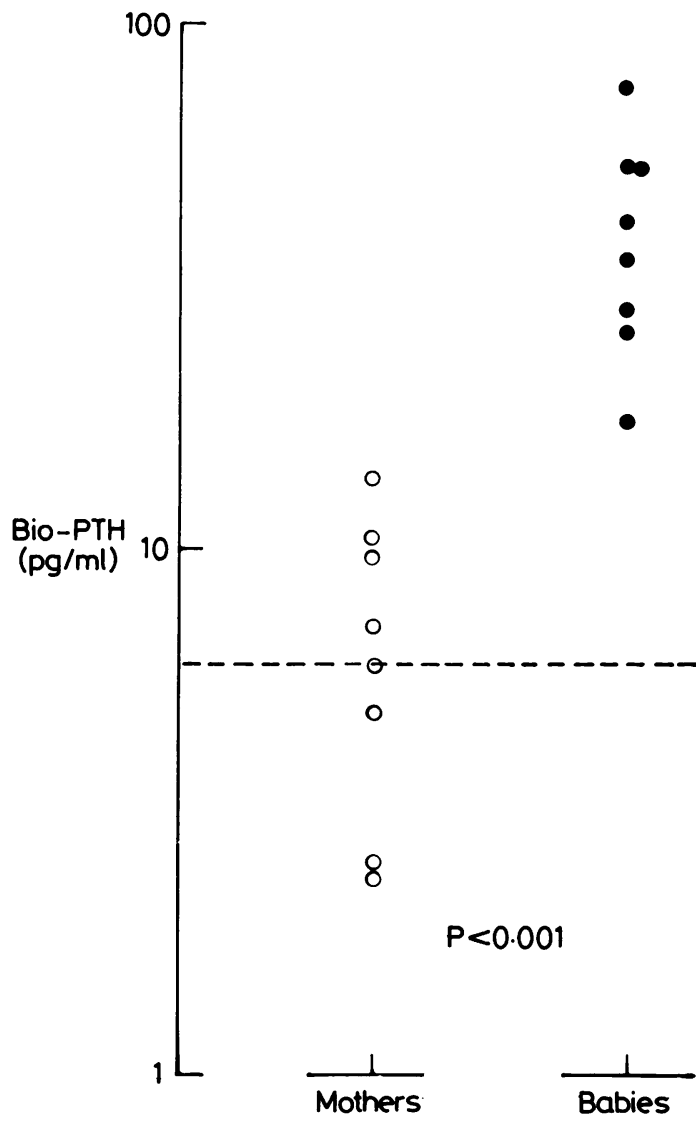

Fig. 2 Parathyroid hormone bioactivity (Bio-PTH) in maternal (open circles) and cord (closed circles) venous plasma.

The upper limit of normal for young adults is represented by the horizontal dotted line.

Fig. 3 Time course of the response (measured as mean integrated extinction) of glucose 6-phosphate dehydrogenase activity to parathyroid hormone in maternal (open circles) and cord (closed circles) venous plasma of one mother-baby pair.

The pattern of response in both is identical, declining from an initial high value at six minutes followed by a second peak at 12 minutes. 


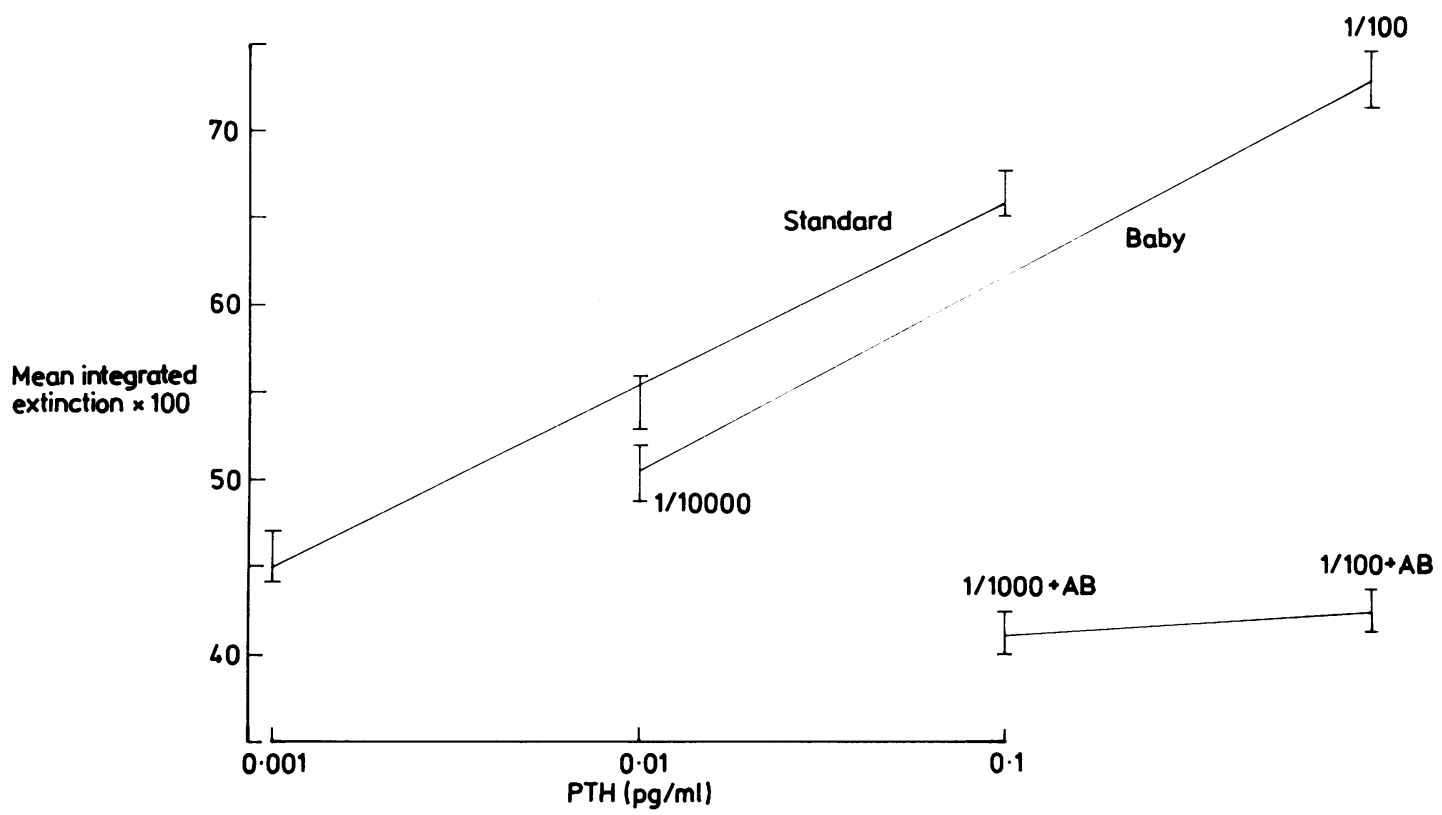

Fig. 4 Effect of addition of amino terminal specific anti-human parathyroid hormone antibody $(A B)$ to cord plasma.

Without antibody the response (measured as mean integrated extinction) is paraliel to that of the standard curve and gives a value of $36 \mathrm{pg} / \mathrm{ml}$. After the addition of antibody the activity falls to below $0.1 \mathrm{pg} / \mathrm{ml}$.

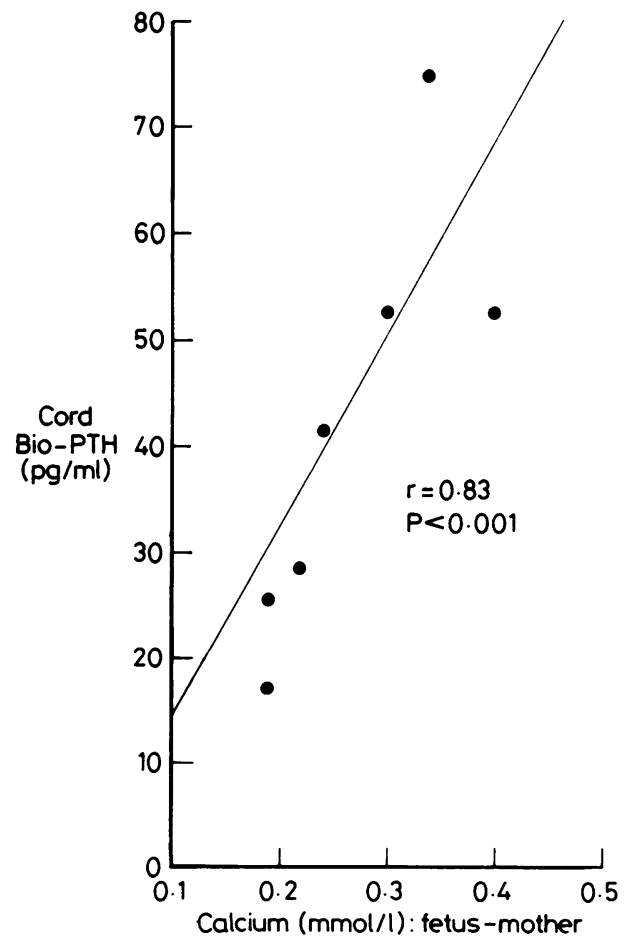

correlation between the gradient of calcium across the placenta and the concentration of bioactive parathyroid hormone in cord blood $(r=.83 \mathrm{P}<0.01)$ (Fig. 5).

\section{Discussion}

The cytochemical bioassay has been shown to be a highly sensitive method of measuring parathyroid hormone, ${ }^{33-35}$ and we have applied it to the measurement of concentrations in fetal and maternal plasma. Activity in the two groups showed parallelism with the standard curve and the similar time courses of response to maternal and fetal plasma indicated that the same substance was being measured in each. The disappearance of activity from fetal plasma when amino terminal specific antihuman parathyroid hormone antibody was added to it confirmed that this substance was parathyroid hormone.

Fig. 5 Correlation between parathyroid hormone (Bio-PTH) bioactivity of cord venous plasma and the transplacental gradient of plasma calcium.

There is a significant positive relation. 
Intact human parathyroid hormone contains 84 amino acids. ${ }^{36}$ Only the first 34 , however, are required for full biological activity. ${ }^{37}$ The concentration of the amino terminus in plasma is normally less than that of the carboxy terminus. This is partly a reflection of the different half lives of fragments from opposite ends of the molecule in plasma ${ }^{38}$ Our results showed that in maternal plasma both the amino terminus and bioactivity were slightly raised, and support the view that late pregnancy is a time of mild physiological hyperparathyroidism. The carboxy terminus however, was not raised. This difference between the amino and carboxy termini of parathyroid hormone helps to explain some of the conflicting results found previously when parathyroid hormone has been measured by immunoassay, and may be related in the pregnant compared with the non-pregnant female to reduced generation or more rapid clearance of carboxy terminus fragments.

Immunoreactive parathyroid hormone, particularly the amino terminus, was lower in fetal than in maternal plasma, an observation which is consistent with the hypothesis that the parathyroid glands are suppressed during fetal life. The greatly increased concentrations of bioactive parathyroid hormone in fetal plasma, however, were surprising and suggested that, despite the low or undetectable concentrations of immunoreactive parathyroid hormone in the fetus, the parathyroid glands are not in fact suppressed. Furthermore, an inverse relation between bioactive parathyroid hormone and plasma calcium, which might be expected to exist if high fetal plasma calcium concentrations do suppress fetal parathyroid gland activity, was not shown. Similarly there was no relation between these two variables in the mothers.

The positive relation between bioactive parathyroid hormone in the fetus and the difference between fetal and maternal calcium was of considerable interest. Since plasma calcium concentrations are higher in the human fetus than in the mother, an active calcium pump clearly exists, and from animal studies, mainly in sheep, ${ }^{39}{ }^{40}$ it is thought that the fetus is largely responsible for this pump. The results of the cytochemical bioassay support this view and suggest that, rather than being suppressed, the fetal parathyroid glands have considerable activity which contributes to the maintenance of the transplacental calcium gradient, possibly by acting, directly or indirectly, on the placenta.

Allowing for the different molecular weights of the standard reference preparations used in the two assay systems, the ratio of the mean values of the amino terminus to bioactivity was no more than $2 \cdot 4: 1$ in fetal plasma and 61:1 in maternal plasma. It therefore seems that, while in normal adults and pregnant women only a very small proportion of circulating amino terminus is biologically active, in cord plasma this proportion is greater than $40 \%$. The reasons for this difference are not clear, but are presumably due to the presence, in adult and maternal plasma, of high concentrations of biologically inactive parathyroid hormone which is also recognised by the immunoassay. The relatively low concentrations of biologically inactive amino terminus of parathyroid hormone in fetal plasma may be due either to a very rapid rate of removal of these fragments from fetal plasma (for example by the placenta), or to differences between mother and fetus in the rate of metabolism of intact parathyroid hormone.

Whatever the explanation for the differences observed in these studies, it is clear that the measurement of parathyroid hormone by cytochemical bioassay has resulted in data which conflict strongly with those of immunoassay, both in the same infants in whom it was measured and when related to the results of previously reported studies. In particular, this is the first report of parathyroid hormone concentrations which were significantly higher in cord blood than in corresponding maternal blood. If parathyroid hormone acted in some way on the placenta, the high concentrations of bioactive parathyroid hormone in cord blood might help to explain how the well recognised gradient of calcium across the placenta is maintained.

J A was supported by Action Research.

We thank Dr J Chayen for providing facilities to undertake the cytochemical bioassays at the Mathilda and Terence Kennedy Institute of Rheumatology and Dr D R Harvey and Dr R Dinwiddie for permission to study their patients at Queen Charlotte's Maternity Hospital.

\section{References}

${ }^{1}$ Mull TW, Bill AH. Variations in serum calcium and phosphorus during pregnancy. I. Normal variations. Am J Obstet Gynecol 1934;27:510-7.

2 Pitkin RM. Calcium metabolism in pregnancy: a review. Am J Obstet Gynecol 1975;121:724-37.

${ }^{3}$ Tan CM, Raman A, Sinnathyray TA. Serum ionic calcium levels during pregnancy. Journal of Obstetrics and Gynaecology of the British Commonwealth 1972;79:694-7.

${ }^{4}$ Pitkin RM, Gebhardt MP. Serum calcium concentrations in human pregnancy. Am J Obstet Gynecol 1977;127:775-8.

5 Reitz RE, Daane TA, Woods TD, Weinstein RL. Calcium, magnesium, phosphorus and parathyroid hormone interrelationships in pregnancy and newborn infants. Obstet Gynecol 1977;50:701-5.

6 Bogert LJ, Plass ED. Placental transmission. I. The calcium and magnesium content of fetal and maternal blood serum. J. Biol Chem 1923;56:297-307.

7 Crawford JS. Maternal and cord blood at delivery. IV. Glucose, sodium, potassium, calcium and chloride. Biol Neonate 1965;8: 222-37. 
8 Armstrong WD, Singer L, Makowski EL. Placental transfer of fluoride and calcium. Am J Obstet Gynecol 1970;107:432-4.

9 Delivoria-Papadopoulos M, Battaglia FC, Bruns PD, Meschia G. Total, protein-bound and ultrafilterable calcium in maternal and fetal plasma. Am J Physiol 1967;213:363-6.

10 Tan CM, Raman A. Maternal-fetal calcium relationships in man. $Q J$ Exp Physiol 1972;57:56-9.

1 Pitkin RM, Cruikshank DP, Schauberger CW, Reynolds WA, Williams GA, Hargis GK. Fetal calciotropic hormones and neonatal calcium homeostasis. Pediatrics 1980;66:77-82.

12 Cushard WG, Creditor MA, Canterbury JM, Reiss E. Physiologic hyperparathyroidism in pregnancy. J Clin Endocrinol Metab 1972;34:767-71.

${ }^{13}$ Root A, Gruskin A, Reber RM, Stopa A, Duckett G. Serum concentrations of parathyroid hormone in infants, children and adolescents. J Pediatr 1974;8:329-36.

14 Tsang RC, Chen I-W, Friedman MA, et al. Parathyroid function in infants of diabetic mothers. $J$ Pediatr 1975;86:399-404.

${ }^{15}$ Hillman LS, Slatopolsky E, Haddad JG. Perinatal vitamin D metabolism in maternal and cord serum. 24,25-dihydroxyvitamin D concentrations. J Clin Endocrinol Metab 1978; 47:1073-7.

16 Wieland P, Fischer JA, Trechsel V, et al. Perinatal parathyroid hormone, vitamin D metabolites and calcitonin in man. Am J Physiol 1980;239:E385-90.

17 Steichen JJ, Tsang RC, Gratton JL, Hamstra A, DeLuca HF. Vitamin D homeostasis in the perinatal period. 1,25 dihydroxy vitamin D in maternal, cord and neonatal blood. $N$ Engl J Med 1980;302:315-9.

${ }^{18}$ Heaney RP, Skillman TG. Calcium metabolism in normal human pregnancy. J Clin Endocrinol Metab 1971;33:661-70.

19 David L, Anast CS. Calcium metabolism in newborn infants. The interrelationships of parathyroid function and calcium, magnesium and phosphorus metabolism in normal, 'sick' and hypocalcemic newborns. J Clin Invest 1974;54:287-96.

20 Fairney $\mathrm{A}$. The role of parathyroid hormone in the aetiology of neonatal hypocalcaemia. Postgrad Med J 1975;51 Suppl 3:18-24.

21 Hillman LS, Rojanasathit S, Slatopolsky E, Haddad JG. Serial measurements of serum calcium, magnesium, parathyroid hormone, calcitonin and 25-hydroxy-vitamin $\mathrm{D}$ in premature and term infants during the first week of life. Pediatr Res 1977;11:739-44

22 Schedewie HK, Odell WD, Fisher DA, et al. Parathormone and perinatal calcium homeostasis. Pediatr Res 1979;131:1-6.

23 Bergman L, Kjellmer I, Selstram U. Calcitonin and parathyroid hormone - relation to early neonatal hypocalcemia in infants of diabetic mothers. Biol Neonate 1974;24:151-60.

24 Tsang RC, Chen I-W, Friedman MA, Chen I. Neonatal parathyroid function: role of gestational age and postnatal age. $J$ Pediatr 1973;83:728-38.

${ }^{25}$ Lequin RM, Hackeng WHL, Schopman W. A radioimmunoassay for parathyroid hormone. Acta Endocrinol 1970;63: $655-66$.
${ }^{26}$ Watney PJM. Maternal factors in the aetiology of neonatal hypocalcaemia. Postgrad Med J 1975;51 Suppl 3:14-7.

${ }^{27}$ Leroyer-Alizon E, David L, Anast CS, Dubois PM. Immunocytological evidence for parathyroid hormone in human fetal parathyroid glands. J Clin Endocrinol Metab 1981;52:513-6.

${ }^{28}$ Scothorne RJ. Functional capacity of fetal parathyroid glands, with reference to their clinical use as homografts. Ann NY Acad Sci 1964;120:669-76.

${ }^{29}$ Pitkin RM, Reynolds WA, Williams GA, Kawahara W, Bauman AF, Hargis GK. Maternal and fetal parathyroid hormone responsiveness in pregnant primates. J Clin Endocrinol Metab 1980;51:1044-7.

${ }^{30}$ Allgrove J, Chayen J, O'Riordan JHL. The cytochemical bioassay of parathyroid hormone: further experience. J Immunoassay 1983;4:1-19.

${ }^{31}$ Papapoulos SE, Manning RM, Hendy GN, Lewin IG, O'Riordan JLH. Studies of circulating parathyroid hormone in man using a homologous amino terminal specific immunoradiometric assay. Clin Endocrinol 1980;13:57-67.

${ }^{32}$ Manning RM, Adami S, Papapoulos SE, O'Riordan JLH. A homologous carboxy terminal specific immunoradiometric assay for human parathyroid hormone. Clin Endocrinol 1981;15: 439-49.

33 Chambers DJ, Dunham J, Zanelli JM, Parsons JA, Bitensky L, Chayen J. A sensitive bioassay of parathyroid hormone in plasma. Clin Endocrinol 1978;9:375-9.

${ }^{34}$ Fenton S, Somers S, Heath DA. Preliminary studies with the cytochemical bioassay for parathyroid hormone. Clin Endocrinol 1978;9:381-4.

${ }^{35}$ Goltzman D, Henderson B, Loveridge N. Cytochemical bioassay of parathyroid hormone: characteristics of the assay and analysis of circulating hormonal forms. J Clin Invest 1980;65: 1309-17.

36 Keutmann HT, Sauer MM, Hendy GN, O'Riordan JLH, Potts JT, Jr. Complete aminoacid sequence of human parathyroid hormone. Biochemistry 1978;17:5723-9.

37 Tregear GW, Van Reitschoten J, Green E, et al. Bovine parathyroid hormone: minimum chain length of synthetic peptide required for biological activity. Endocrinology 1973;93: 1349-53.

38 Papapoulos SE, Hendy GN, Tomlinson S, Lewin IG, O'Riordan JLH. Clearance of exogenous parathyroid hormone in normal and uraemic man. Clin Endocrinol 1977;7:211-5.

39 Symonds HW, Sansom BF, Twardock AR. The measurement of the transfer of calcium and phosphorus from fetus to dam in the sheep using a whole body counter. Res Vet Sci 1972;13:272-5.

40 Care AD, Dutton A, Mott JC, Robinson JS, Ross R. Studies of the transplacental calcium gradient in the sheep. $J$ Physiol (Lond) 1979;290:19P-20P.

Correspondence to Dr J Allgrove, Department of Paediatrics, East Birmingham Hospital, Birmingham B9 5ST.

Received 15 October 1984. 